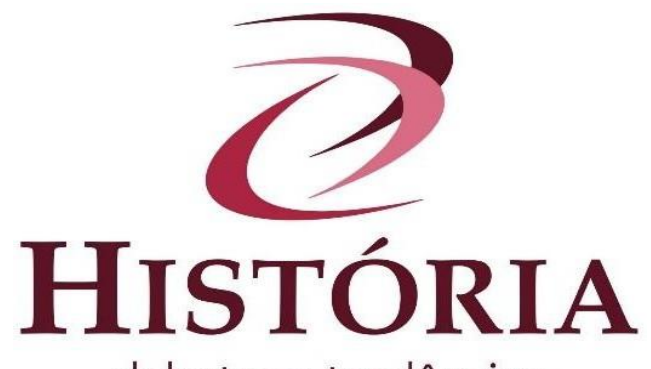

\title{
Charles Darwin: ateísmo e evolucionismo no século XIX
}

\section{Charles Darwin: Atheism and Evolutionism in the 19th Century}

\author{
Charles Darwin: el ateísmo y el evolucionismo en el siglo XIX
}

Resumo: O presente artigo aborda a concepção evolucionista desenvolvida pelo naturalista inglês Charles Darwin (1809-1882) sobre o mundo natural em A origem das espécies (1859) e sobre o ser humano em A origem do homem e a seleção sexual (1871). Antes disso, fazse uma discussão em torno da relação de Darwin com o ateísmo, uma vez que suas ideias representaram uma fratura na cosmovisão judaico-cristã cultivada na história do Ocidente, e sua figura se tornou um referencial no trabalho de muitos ateístas no início do século XXI. Palavras-chave: Ateísmo. Charles Darwin. Evolucionismo.

Abstract: In the present article we will address the evolutionary conception developed by the English naturalist Charles Darwin (1809-1882) on the natural world in The Origin of Species (1859) and on the human being in The Origin of Man and Sexual Selection (1871). Before that, we will discuss Darwin's relationship with atheism, since his ideas represented a fracture in the Judeo-Christian worldview cultivated in the history of the West, and his figure became a benchmark in the work of many early atheists of the 21 st century.

Keywords: Atheism. Charles Darwin. Evolutionism.

Resumen: En el presente artículo abordaremos la concepción evolutiva desarrollada por el naturalista inglés Charles Darwin (1809-1882) sobre el mundo natural en El origen de las especies (1859) y sobre el ser humano en El origen del hombre y la selección sexual (1871). Antes de eso, discutiremos la relación de Charles Darwin con el ateísmo, ya que sus ideas representaron una fractura en la cosmovisión judeocristiana cultivada en la historia de Occidente, y su figura se convirtió en un punto de referencia en el trabajo de muchos de los primeros ateos del siglo XXI.

Palabras clave: Ateísmo. Charles Darwin. Evolucionismo.

\section{Introdução}

Se muitas espécies pertencentes aos mesmos gêneros ou às mesmas famílias tivessem iniciado sua vida em um único momento, esse fato seria fatal para a teoria da descendência com lentas modificações efetuadas pela seleção natural. (Charles Darwin, A Origem das Espécies)

O homem, juntamente com os outros mamíferos, 
descende de um antepassado comum. (Charles Darwin, A Origem do Homem)

A partir de 2018, meu interesse se voltou para o estudo do ateísmo. Dito de modo mais preciso, optei por pesquisar as origens e características das ideias ateístas na história do Brasil. Essa decisão fez com que eu procurasse conhecer mais sistematicamente as concepções na área da filosofia e na área da ciência historicamente utilizadas para fundamentar visões de mundo ateístas. Uma dessas concepções surgiu no século XIX com a divulgação dos trabalhos do naturalista inglês Charles Darwin, particularmente os livros A origem das espécies e A origem do homem e a seleção sexual. São aos trabalhos desse naturalista a que irei me reportar nesse artigo.

A origem das espécies, publicada em 1859, foi uma interpretação alternativa - e também conflitante - à forma como a origem do mundo e do ser humano, com respaldo nos textos bíblicos, foi apresentada ao longo dos séculos pelo cristianismo, religião que tinha enorme influência social e cultural no cenário inglês do século XIX. Consciente dessa situação, Darwin foi cauteloso em apresentar uma análise naturalista do ser humano, o que ocorreu apenas em 1871, com a publicação de A origem do homem e a seleção sexual. E ele manteve-se, apesar dessa obra, bastante reservado em expor publicamente opiniões sobre religião e a fé em Deus.

Nesse início de século XXI, a teoria da evolução apresentada nas páginas de $A$ origem das espécies é um dos pilares de uma cosmovisão ateísta, e seu autor, Charles Darwin, uma figura simbólica para muitos ateus. Entender essa relação do naturalista inglês com o ateísmo, e os elementos em seu trabalho científico que representaram uma fratura na narrativa religiosa sobre o que seria o ser humano, é o principal objetivo desse artigo. Para realizar essa tarefa, o texto apresenta três principais metas: a) uma abordagem da relação entre Darwin e o ateísmo; b) a exposição dos pressupostos básicos da teoria da evolução em A origem das espécies; c) a concepção evolucionista sobre o ser humano na obra A origem do homem e a seleção sexual.

\section{Charles Darwin e o ateísmo}

Em 1880, Charles Darwin escreveu em uma carta em que dizia: "Lamento ter de informá-lo que não acredito na Bíblia como revelação divina e, portanto, tampouco em Jesus Cristo como o filho de Deus". Essa afirmação foi endereçada ao jovem advogado Francis 
McDermott, que antes de iniciar a leitura de seus livros pediu uma resposta clara, no sentido de "sim" ou "não", se o naturalista acreditava no Novo Testamento. (LAMENTO, 2015). Mais de um século após o falecimento do cientista inglês, grupos ateístas no Brasil e em outras partes do mundo optaram por comemorar em todo o dia 12 de fevereiro o chamado Dia do Orgulho Ateu: "A data foi escolhida em homenagem ao nascimento do naturalista britânico Charles Darwin (1809-1882). Com sua teoria da evolução por meio da seleção natural, no livro A origem das espécies, de 1859, Darwin refutou parte fundamental do discurso religioso: a Criação" (FREITAS, 2015, p. 1).

Mas é preciso certa cautela com essa identificação. Para Nelio Bizzo, "a ideia de que Charles Darwin tenha sido um paladino do materialismo, difundindo ativamente o ateísmo, é uma ideia equivocada" (2013, p. 301). Além disso, Darwin não teria deixado de reverenciar e mesmo admitir a necessidade de um Criador, o que poderia ser comprovado através da análise das modificações introduzidas por ele nas edições do livro A origem das espécies entre 1859, ocasião da primeira edição, e 1872, quando foi lançada a sexta edição com as últimas modificações feitas pelo naturalista inglês. Um caso dessas mudanças apareceu na segunda edição da obra, publicada apenas seis semanas depois da primeira, na qual foi acrescentada - ao final da afirmação de que todos os seres orgânicos que já viveram sobre a Terra eram descendentes de uma forma primordial, na qual a vida foi inicialmente soprada - o trecho “pelo Criador". Porém, na edição de 1872 essa parte já não constava mais, tendo sido suprimida. Apesar dessas ressalvas, "dizer que o darwinismo seja plenamente compatível com a religião seria uma afirmação enganadora, dado que ele é associado muito fortemente, ao contrário, com o ateísmo" (BIZZO, 2013, p. 329).

A relação de Darwin com a religião e o ateísmo também aparece no livro A goleada de Darwin, de Sandro de Souza. Esse autor apresentou dados biográficos sobre o naturalista britânico: Charles Darwin nasceu na Inglaterra em 1809, na pequena cidade de Shrewsbury. Seu pai, Robert, “vinha de uma família muito liberal e reconhecidamente ateísta. Sua mãe, Susannah, vinha de uma família também abastada, porém mais conservadora e extremamente religiosa, os Wedgwoods" (SOUZA, 2009, p. 23). A sua formação intelectual inicialmente foi em medicina, na Universidade de Edimburgo, na Escócia, a partir de 1825. Porém, ao perceber o pouco interesse do filho pela área, Robert Darwin o encaminhou para o Christ's College, em Cambridge, com a finalidade de torná-lo clérigo da Igreja Anglicana. Naquele ambiente cresceu o interesse de Darwin pelas ciências naturais, impulsionado pela amizade com o botânico John Henslow, defensor da compatibilidade entre a religião e os estudos das ciências naturais. Em 1831 ele terminou os estudos: "Os exames finais em 
Cambridge representavam a sua ordenação para clérigo, e a possibilidade de se tornar um clérigo naturalista nos moldes de Henslow [...]" (idem, ibidem, p. 24).

Os planos de vida de Charles Darwin tiveram uma reviravolta em agosto de 1831 quando, por meio de John Henslow, foi convidado a participar de uma viagem ao redor do mundo a bordo do barco da marinha britânica HMS Beagle. A jornada do Beagle tinha como objetivo a tomada de medidas cartográficas em diferentes pontos do mundo. Darwin aproveitou a ocasião para pesquisar e catalogar as diversas espécimes de seres vivos que encontrava pelo caminho. O material recolhido na viagem foi central para a formulação da teoria da seleção natural, uma das ideias fundamentais de $A$ origem das espécies. E é sobre o episódio dessa viagem que Sandro de Souza aborda a discussão sobre a relação de Darwin com religião e ateísmo. Conforme o autor, "ao subir a bordo do Beagle, em dezembro de 1831, Darwin certamente acreditava que o mundo refletia uma tradução literal da Bíblia" (SOUZA, 2009, p. 167). Contudo,

Todos os seus biógrafos concordam que ao morrer, em abril de 1882, era [Darwin] um agnóstico, se não um ateu. Quando exatamente a fé foi perdida é matéria de debate. Ao desembarcar do Beagle em outubro de 1836, havia deixado de acreditar nos fatos descritos da Bíblia como verdadeiros. [...] Embora a descrença na Bíblia tenha surgido durante a viagem do Beagle, o abandono total do cristianismo só veio a ocorrer por volta de 1849 , conforme dito pelo próprio Darwin: "Nunca desisti do cristianismo até os meus 40 anos" (SOUZA, 2009, p. 168).

Para Sandro de Souza, a perda do alicerce emocional que sustentou a crença inicial de Darwin no cristianismo foi fruto de um processo lento, porém bastante lógico. E isso envolveu dois aspectos racionais e um emocional. O primeiro aspecto racional surgiu da crítica de Darwin à crença de que aqueles que não tivessem uma interpretação literal dos textos bíblicos estariam condenados pela eternidade. A sua formação humanista o levou a ver tal princípio como fruto de uma doutrina diabólica. O segundo aspecto racional apareceu por meio do seu lado científico: o cristianismo não seria respaldado por provas. Já o aspecto emocional esteve ligado a perda de pessoas próximas. A primeira perda foi o pai, que faleceu em 1848, e a segunda foi a filha Annie de nove anos, falecida em 1851. Annie era a filha mais velha e a predileta de Darwin. Ele testemunhou o seu sofrimento sem conseguir ajudála a vencer a batalha contra a doença do tifo. Assim, "a perda em tais circunstâncias praticamente decretou a morte de qualquer vestígio de crença [religiosa] que porventura ainda existisse em Darwin" (SOUZA, 2009, p. 169).

Apesar do processo de descrença no cristianismo, Charles Darwin muitas vezes foi 
ambíguo sobre o tema da fé, como se procurasse um meio-termo que o satisfizesse. Essa é a posição de Sandro de Souza com base na análise da correspondência do naturalista britânico. Por exemplo: Darwin ficou feliz em receber as cartas do clérigo anglicano Charles Kingsley e do estadunidense Asa Gray, os quais não viam de forma conflitante as teses evolutivas de Darwin com a fé cristã. Para Asa Gray, "o darwinismo se focava nas causas secundárias, mostrando que a evolução das espécies obedecia a determinadas leis. As causas primárias, segundo Gray, ainda estavam em aberto e sujeitas a interpretações metafísicas" (SOUZA, 2009, p. 170).

Além da ambiguidade, "muitas vezes Darwin demonstrava um claro receio de entrar em discussões de cunho religioso" (SOUZA, 2009, p. 171). Para Sandro de Souza, uma das razões para esse receio era de ordem familiar. A esposa de Darwin provinha de uma família conservadora e religiosa. Emma ficou chocada quando Darwin lhe confessou, antes do casamento, que tinha dúvidas sobre a fé. Ela temia que com essa posição Darwin fosse para o inferno após a morte. Um segundo fator que contribuiu para o receio de Darwin foi a instabilidade política e social na Inglaterra com a ascensão das formas de organização e de luta da classe trabalhadora. Charles Darwin temia que sua obra, de teor materialista e que chegou a atrair a atenção de uma das principais lideranças do movimento operário europeu, o filósofo alemão Karl Marx (1818-1883), pudesse ser usada para legitimar rebeliões sociais (SOUZA, 2009).

No decorrer da vida Charles Darwin acabou por se definir por meio da palavra criada pelo biólogo e amigo Thomas Huxley (1825-1895): agnóstico. Palavra de origem grega, em que o prefixo a significa ausência e o radical gnose refere-se a conhecimento. Assim, agnóstico é aquele que não possui conhecimento suficiente para afirmar se Deus existe ou não. Para Nelio Bizzo, “A palavra parecia perfeita como rótulo discreto de ateísmo [...] evitava o confronto com a crença em Deus" (BIZZO, 2013, p. 331). Esta foi uma identidade que Darwin assumiu de forma reservada e em âmbito privado. Na carta endereçada a Francis McDermott, por exemplo, ele pediu que o advogado mantivesse em sigilo a resposta sobre sua descrença na Bíblia. E isso aconteceu. A carta só se tornou pública um século após a morte de Darwin (LAMENTO, 2015).

As discussões sobre a relação de Charles Darwin com a religião e o agnosticismo e/ou ateísmo, potencializadas após a publicação de A origem das espécies, se estenderam ao longo do século XX e chegaram ao XXI. Ao ressaltar a postura de descrença religiosa de Darwin, ateus e agnósticos buscam em sua figura uma fonte de legitimação para o ateísmo como uma atitude socialmente plausível. Por outro lado, ao destacar as ambiguidades de 
Darwin sobre os temas da fé, muitos adeptos de crenças religiosas tentam enclausurar o ateísmo em um gueto social e intelectual. Mas independentemente de até que ponto Charles Darwin se distanciou ou não da fé religiosa, suas teses evolucionistas significaram uma ruptura na narrativa bíblica sobre a origem da vida.

\section{A teoria da evolução em $A$ origem das espécies}

Em 24 de novembro de 1859 foi publicado na Inglaterra o livro Sobre a origem das espécies por meio da seleção natural ou A preservação de raças favorecidas na luta pela vida. Em 1872, com a publicação da sexta edição, o título foi abreviado para A origem das espécies. A teoria evolucionista presente neste livro causou grande impacto na época de sua divulgação, e ainda hoje influencia diversas áreas do conhecimento humano. De acordo com André Luis de Lima Carvalho, "a filosofia inerente ao discurso de Darwin trazia em seu bojo concepções muito ameaçadoras aos valores e doutrinas teológicas então predominantes" (CARVALHO, 2005, p. 18). Para Eric Hobsbawm, Darwin colocou o homem no quadro da evolução biológica e, com isso, aboliu a linha divisória entre ciências naturais, humanas ou sociais (HOBSBAWM, 2011).

Para entender melhor o impacto das teses apresentadas por Darwin em A origem das espécies, penso que é importante oferecer mais detalhes da cosmovisão predominante sobre o mundo e os seres vivos até meados do século XIX. Segundo Sandro de Souza, a obra darwiniana foi mais um capítulo no processo crescente de divergência entre a interpretação de mundo feita pelas religiões, particularmente a judaica e a cristã, e as descobertas científicas que vinham se acumulando desde a Idade Moderna. As respostas da Igreja e de grupos religiosos a essas discrepâncias foram se aprimorando de ameaças de excomunhão ou morte na fogueira para retóricas que tentavam tornar compatível os princípios religiosos com os avanços científicos. No século XVII, por exemplo, o arcebispo irlandês James Ussher, baseado nas genealogias dadas pela Bíblia, indicou que o ano de criação do mundo teria sido 4004 a.c. (SOUZA, 2009).

Os argumentos que teólogos e instituições religiosas contrapuseram às verdades estabelecidas pelo discurso científico também tiveram um respaldo filosófico. Um desses respaldos foi Aristóteles (384 a.c - 322 a.c). Em sua obra, o filósofo grego afirma que a essência de um processo de investigação sobre qualquer coisa natural reside na resposta a quatro perguntas básicas: 1) do que a coisa é feita; 2) qual é a forma ou estrutura da coisa; 3) como foi o início da coisa; 4) qual o propósito da coisa. Em face do grau de importância 
das questões, Aristóteles deu a última questão um nome específico, télos. Ou seja, todas as coisas no mundo natural existiriam para cumprir uma finalidade (SOUZA, 2009). Sobre isso Nelio Bizzo assim escreve:

\begin{abstract}
Estava bem assentada em Aristóteles a ideia de equilíbrio estático na Natureza, vista como eterna e imutável, na qual não há carência nem desperdício, que nada falta ou excede ao necessário, que cada característica tem uma finalidade específica a explicar sua existência, e que nada ocorre por acaso. Essa imagem, depois de cristianizada, compatibilizada com a ideia de um início (Gênesis) e fim (Apocalipse), é o alicerce invariável da visão dogmática dos criacionistas da linha judaico-cristã e maometana até nossos dias (BIZZO, 2018, p. 1718).
\end{abstract}

Contudo, as descobertas científicas de Charles Darwin foram favorecidas por ideias evolucionistas de períodos anteriores. No artigo A teoria evolutiva de Darwin e o contexto histórico, Leandro Freitas indica que as primeiras referências sobre a adaptação das espécies surgiram em escritos de autores da Grécia Antiga, como Anaximandro (610546 a.c.), Anaxágoras (500-428 a.c.), Demócrito (460-370 a.c) e Hipócrates (460-370 a.c). Já na era cristã, o teólogo Agostinho de Hipona (354-430) interpretou que não só produtos finais haviam sido criados no início, mas que muitas criações de Deus recebiam o potencial para produzirem organismos. Apesar disso, "o desenvolvimento efetivo das teorias evolutivas ocorreu a partir do século XVIII e requereu um rompimento com o pensamento ocidental da época, centrado na imutabilidade de um universo projetado por um Criador" (FREITAS, 1998, p. 56). A discussão entre criação e descendência dos seres vivos, "até então limitada a teólogos, filósofos e leigos, tornou-se no século XVIII uma questão fundamental para naturalistas" (idem, ibidem, p. 56).

Na virada do século XVIII para o XIX as ideias evolucionistas ganharam destaque por meio da figura do naturalista francês Jean-Baptiste de Lamarck (1744-1829), o qual afirmou que haviam duas causas responsáveis pelas mudanças nos seres vivos. A primeira era um dote que permitia a aquisição de maior complexidade (perfeição), sendo esta tendência derivada da força conferida pelo supremo autor de todas as coisas (Deus). A segunda causa era a capacidade de reação a condições especiais do ambiente. Apoiado nestas duas causas, Lamarck fundamentou o antigo conceito de fortalecimento de um órgão pelo uso e o enfraquecimento pelo desuso, "o qual denominou de 'Primeira Lei'. A 'Segunda Lei' trata da herança dos caracteres adquiridos [...] ou perdidas por indivíduos, como resultado da influência das condições ambientais [...] transmitidas para os indivíduos descendentes" (FREITAS, 1998, p. 56). 
Em 1844, foi publicado Vestiges of the Natural History of Creation, de autoria do britânico e estudioso de biologia Robert Chambers (1802-1871). Nele, Chambers afirmou que a fauna do mundo evoluiu no decorrer do tempo geológico e que as mudanças foram lentas e graduais, não estando relacionadas com nenhum evento catastrófico no ambiente. Em 1852, o botânico vienense Franz Unger (1800-1870), em Attempt of a History of Plant World, indicou que as causas da diversidade das plantas eram internas e não externas, e que novas espécies de plantas se originavam de outras plantas. Para Leandro Freitas, estes trabalhos estimularam o desenvolvimento do pensamento evolutivo. Através da defesa da descendência comum, da importância das condições ambientais e do reconhecimento da variabilidade das espécies, "estas teorias rompem com o essencialismo, com o fixismo, com o mecanicismo, com o reducionismo, e principalmente, com o criacionismo teleológico [...]" (FREITAS, 1998, p. 57).

Apesar da existência de análises de viés evolucionista sobre o mundo natural, como os exemplos elencados nos parágrafos anteriores, A origem das espécies teve um impacto que nenhuma obra até então obtivera na área das ciências naturais. O conteúdo do livro de Charles Darwin foi amarrado por meio de duas teses principais: 1) todos os organismos descendem com modificação a partir de ancestrais comuns (tese da descendência comum); 2) o agente desta modificação era a seleção natural. Para expor as ideias desse livro na presente publicação, lanço mão de uma edição publicada no Brasil em 2018 pela Edipro. A tradução desta edição foi feita com base no texto da primeira edição de $A$ origem das espécies, de 1859, que depois passou por alterações elaboradas pelo próprio Darwin, em consequência das pressões da impressa e da comunidade científica do século XIX. Para Nelio Bizzo, um dos principais especialistas em darwinismo no Brasil e que foi o responsável pelo prefácio, pela revisão técnica e pelas notas de rodapé da citada tradução, “A versão original traz a radicalidade de suas ideias [Darwin] exposta de forma direta, sem requerer do leitor o conhecimento das reações do grande público" (BIZZO, 2018, p. 11).

A tese da descendência comum foi exposta já na introdução da obra, logo após Charles Darwin comentar que resolveu escrever o livro com apoio das análises que fez do material recolhido por ele ao redor do mundo durante a viagem no HMS Beagle entre 1831 e 1836. Mediante essas pesquisas, afirmou: "Estou plenamente convencido de que as espécies não são imutáveis; mas que aquelas pertencentes àquilo que chamamos de mesmo gênero são descendentes diretas de algumas outras espécies que geralmente estão extintas [...]" (DARWIN, 2018, p. 29).

Ainda que bem fundamentada, para Darwin essa conclusão seria insatisfatória até 
que pudesse ser demonstrado como as inúmeras espécies que habitavam o mundo foram modificadas até atingir o estágio atual. Os naturalistas costumavam dizer que as condições externas, como clima e disponibilidade de alimentos, eram as únicas causas possíveis de gerar variações nas espécies. Essa afirmação teria sua dose de verdade, mas não seria capaz de explicar a complexidade dos mecanismos envolvidos no processo de variação das espécies. E nesse ponto reside a importância do primeiro e do segundo capítulos de A origem das espécies, com a discussão sobre a variação doméstica e na natureza. De acordo com Darwin, a observação de casos domésticos, somados aos casos do ambiente natural, comprovariam que as espécies apresentavam um grande potencial de variabilidade e, ainda que influenciado por muitos fatores, ela era favorecida por mudanças hereditárias provocadas pelo sistema reprodutivo (DARWIN, 2018).

A variabilidade das espécies indicaria a ocorrência de mudanças nos seres vivos ao longo do tempo. Porém, como surgiriam os grupos de espécies que constituiriam os chamados gêneros distintos e que diferiam entre si mais do que as espécies do mesmo gênero? Darwin respondeu a essa pergunta no terceiro capítulo, em que expõe a sua segunda tese, qual seja, a de que a variabilidade das espécies ocorre pelo processo de seleção natural, fruto da luta pela existência:

\footnotetext{
Devido a essa luta pela vida, quando qualquer variação, mesmo que pequena e independentemente da razão que a originou, oferece qualquer grau de vantagem para um indivíduo de qualquer espécie nas suas relações infinitamente complexas com os outros seres orgânicos e com a natureza externa, esta tende à preservação do indivíduo e geralmente será herdada por seus descendentes. Dessa forma, a prole também terá mais chance de sobreviver, pois, dos muitos indivíduos de qualquer espécie que nascem periodicamente, apenas um pequeno número consegue sobreviver. A esse princípio, por meio do qual cada pequena variação, quando útil, é preservada, eu chamo seleção natural [...] (DARWIN, 2018, p. 81).
}

De acordo com Darwin, a luta pela existência incluiria não só a vida do indivíduo, mas o sucesso em deixar descendentes. Essa luta decorreria em virtude da alta taxa de crescimento de todos os seres orgânicos. Na medida em que seriam produzidos mais indivíduos do que os que poderiam sobreviver, "deve sempre existir uma luta pela existência, ou de um indivíduo contra outro da mesma espécie ou contra os indivíduos de espécies distintas ou contra as condições físicas da vida" (DARWIN, 2018, p. 83). O naturalista inglês afirmou que essa era a teoria de Thomas Malthus (1766-1834) aplicada com forças múltiplas no reino animal e vegetal. Malthus foi um economista britânico que em 1798 publicou o livro Ensaio sobre o princípio da população, em que defendeu a tese de que a fome entre as populações humanas seria inevitável, uma vez que a produção de 
alimentos ocorria em progressão aritmética, e a população humana crescia em proporção geométrica. Darwin leu essa obra e reconheceu sua influência para o desenvolvimento da teoria de seleção natural via luta pela sobrevivência.

Entre os fatores que determinariam a luta pela sobrevivência estaria a disputa por alimentos, não disponível em quantidade suficiente para todos os seres vivos. Entretanto, outras causas poderiam influenciar no controle do tamanho da população das espécies: variações climáticas severas, como frios intensos e secas prolongadas, e epidemias provocadas por doenças. A questão sexual também teria influência nesse embate pela existência. No quarto capítulo, Charles Darwin dissertou sobre o que chamou de seleção sexual, fator que não dependeria da luta pela existência, mas de uma luta entre os machos pela posse das fêmeas. $\mathrm{O}$ resultado não seria a morte do concorrente sem sucesso, mas a redução parcial ou total de seus descendentes: "os machos mais vigorosos, aqueles que estão mais bem adaptados para assumir seus postos na Natureza, vão deixar um maior número de descendentes" (DARWIN, 2018, p. 106).

Com base no material a que teve acesso e nas análises que fez, Darwin reconheceu a existência de gradações em todos os órgãos ou instintos imagináveis, cada uma delas boa para seu tipo, e que existiria uma luta pela existência que levaria à preservação de todos os desvios estruturais ou instintos vantajosos aos seres vivos. A partir de tais proposições, arrematou:

Embora eu esteja plenamente convencido da verdade das hipóteses resumidas oferecidas neste livro, de forma alguma espero convencer os naturalistas experientes cujas mentes estão cheias de fatos vistos ao longo dos anos a partir de uma perspectiva oposta à minha. É tão fácil esconder nossa ignorância por detrás de frases como "plano da criação", "unidade de design", etc. e, assim, imaginar que demos uma explicação, quando estamos apenas reafirmando um fato (DARWIN, 2018, p. 471).

A citação acima torna explícita, e eu diria de uma forma ousada, o divórcio entre as ideias evolucionistas de Darwin e a visão estática e imutável sobre o mundo natural legada pela tradição filosófica aristotélica e criacionista da tradição judaico-cristã. E, apesar de toda essa radicalidade, houve um tema tabu em A origem das espécies: o ser humano. Charles Darwin demorou para situar esse elemento no processo evolutivo, o que acabou ocorrendo em um livro de início da década de 1870, consagrando definitivamente o “divórcio intelectual” com uma visão de mundo religiosa. 


\section{A concepção evolucionista sobre o ser humano em $A$ origem do homem}

Charles Darwin tinha consciência das implicações que a teoria da evolução poderia ter no campo da teologia. De acordo com Sandro de Souza, "isso sempre foi um assunto que assustava Darwin, tanto que em A origem das espécies pouco se escreveu sobre a espécie humana" (SOUZA, 2009, p. 33). Segundo André Luis de Lima Carvalho, em estilo estrategicamente evasivo o naturalista britânico fez apenas duas breves referências à evolução humana na obra de 1859. Uma delas ocorreu ao discorrer sobre o papel que a seleção natural e a seleção sexual teriam na formação dos seres humanos, e a outra apareceu no último capítulo, quando comentou sobre o desenvolvimento das pesquisas científicas na elucidação da história humana: "Vejo, no futuro distante, a abertura de campos de pesquisa muito mais importantes. A psicologia terá uma nova fundação, a saber, a necessária aquisição gradual de cada poder e capacidade mental. Luz será lançada sobre a origem do homem e sua história" (DARWIN, 2018, p. 477).

Apesar da discrição de Darwin, A origem das espécies significou uma fratura na narrativa judaico-cristã sobre o ser humano. Ainda assim, o pensamento cristão se manteve enraizado na cultura europeia oitocentista, de modo que as teorias darwinistas apenas gradualmente conquistaram legitimidade social e acadêmica - conquista até os dias de hoje incompleta. Conforme Juanma Sánchez Arteaga, durante o século XIX o debate biológico em torno da origem natural do ser humano ficou marcado por uma "confrontação metaempírica [...] entre o evolucionismo materialista e progressista das ciências naturais e a antropogenia [...] dualista (dualismo alma versus corpo humano) defendida pela religião cristã" (ARTEAGA, 2008, p. 373). Outro fato digno de menção é que foi no contexto de publicação do trabalho de Charles Darwin que apareceu a palavra criacionismo. Até então, o estudo sobre o mundo natural com respaldo teológico era denominado de teologia natural: “o termo criacionismo passou a ser amplamente usado no século XIX com o estabelecimento do evolucionismo" (SOUZA, 2009, p. 45).

Ao longo dos anos 1860 alguns episódios fortaleceram as ideias evolucionistas de Darwin no interior da sociedade inglesa. No início dessa década, foi criado o X-Club, formado por adeptos do evolucionismo como Thomas Huxley, John Tyndal, Herbert Spencer e Joseph Hooker, e que, entre outros objetivos, buscava debater e divulgar as teses darwinistas ao ajudar na formação de novos naturalistas, criar periódicos científicos e participar de comitês governamentais. Além disso, surgiram obras que corroboraram as teses darwinistas e tocaram na sensível questão do papel do ser humano na teoria 
evolucionista: em 1863 apareceu a obra $A$ antiguidade do homem, em que o geólogo britânico Charles Lyell (1797-1875) apresentou evidências geológicas de que o ser humano seria muito mais antigo do que afirmavam os relatos bíblicos, e Evidências do lugar do homem na natureza, obra do inglês Thomas Huxley que abordou a origem biológica comum entre os homens e os primatas (CARVALHO, 2005).

Após mais de uma década da publicação de A origem das espécies, Charles Darwin encarou o desafio de falar de que modo compreendia os seres humanos no interior do quadro da teoria da evolução. Isso apareceu em um livro de 1871: A origem do homem e a seleção sexual. Ele escreveu que a obra teria a finalidade única de considerar "em primeiro lugar, se o homem, como qualquer outra espécie, descendeu de outra forma qualquer preexistente; em segundo lugar, a maneira deste desenvolvimento e, em terceiro lugar, o valor das diferenças entre as assim chamadas raças humanas" (DARWIN, 1974, p. 12).

A discussão apresentada por Darwin nos primeiros capítulos do livro foi no sentido de responder afirmativamente à hipótese de o homem compartilhar de uma descendência comum com outros seres vivos, como, por exemplo, ao tratar do tema da constituição física do ser humano. A estrutura física do homem teria o mesmo modelo de outros mamíferos: "Todos os ossos do seu esqueleto podem ser cotejados com os ossos correspondentes de um macaco, de um morcego ou de uma foca" (idem, ibidem, p. 16). A mesma homologia poderia ser dita em relação aos músculos, nervos, vasos sanguíneos e órgãos internos do ser humano, o qual teria semelhanças com a de outros mamíferos e indicaria uma prova para a tese de um antepassado comum.

Acoplada a tese da descendência comum está o tema da variabilidade. Darwin abordou esse tema em A origem das espécies e o retomou na obra de 1871 ao dissertar sobre o ser humano. Conforme o naturalista britânico, os homens também estiveram sujeitos ao fenômeno da variabilidade, influenciados por mudanças ocorridas no meio ambiente em que viviam, nos efeitos do uso e não uso das partes do corpo físico e no legado hereditário. Tudo isso como consequência da seleção natural: "Os primeiros antepassados do homem devem ter tido também, como todos os outros animais, a ter um incremento além dos seus meios de subsistência; e por isso [...] devem ter sido expostos a luta pela existência e [...] a uma rígida lei de seleção natural" (DARWIN, 1974, p. 63). E foi em decorrência da seleção natural que o ser humano acabou favorecido por variações que lhe ocorreram, incorporando aquelas que seriam benéficas e eliminando aquelas que seriam danosas. Um processo igualmente estimulado por ações de caráter individual: o homem inventou a linguagem articulada, descobriu a arte de fazer o fogo, por meio do qual as raízes duras e fibrosas se 
tornaram digeríveis, e foi capaz de construir armadilhas e inúmeros instrumentos. Estas numerosas invenções, "por força das quais o homem primitivo se tornou predominante, constituem resultado direto do desenvolvimento de seus poderes de observação, memória, curiosidade, imaginação e razão" (idem, ibidem, p. 64).

Contudo, Darwin frisou que as variações acarretadas por ações individuais tiveram como base transformações na estrutura física. Entre estas mudanças, uma das mais importantes foi a aquisição da forma bípede. Para o naturalista britânico, tão logo um antigo membro da grande série dos primatas foi induzido a viver menos nas árvores por causa de uma mudança na sua maneira de providenciar os meios para viver ou por força de alguma alteração nas condições ambientais, o seu modo habitual de ser modificou-se: "as mãos e os braços dificilmente se teriam aperfeiçoado a tal ponto de fabricar instrumentos e arremessar pedras e lanças com uma mira precisa até que fossem habitualmente usadas para a locomoção e para sustentar o peso do corpo [...]" (ibidem, p. 67).

Outro tema que Darwin destacou em torno da tese da descendência comum do ser humano com outros seres vivos foi relativo às faculdades mentais. Ele procurou demonstrar que não existiriam diferenças fundamentais entre o homem e outros mamíferos superiores nesse quesito. $\mathrm{O}$ homem possuiria alguns instintos também presente entre animais, "como aquele de autoconservação, do amor sexual, da afeição pela mãe e pelos recém-nascidos, pelo desejo que estes últimos possuem de ser aleitados [...]” (ibidem, p. 85). E emoções mais complexas também seriam comuns aos animais superiores e ao homem: "um cachorro que carrega um cestinho para o seu dono revela em alto grau autoprazer e orgulho" (ibidem, p. 90). Para o naturalista inglês, os homens e os animais superiores, especialmente os primatas, compartilhariam alguns instintos, como paixões, afeições, e "possuem as mesmas faculdades de imitação, atenção, decisão, escolha, memória, imaginação, associação de ideias e também a razão, embora em níveis muito diversos" (ibidem, p. 99).

Na questão da crença religiosa, Darwin foi taxativo: "Não existe prova de que o homem originariamente fosse dotado da nobre fé na existência de um Deus onipotente" (DARWIN, 1974, p. 115-16). Na sequência do mesmo parágrafo ele escreveu que esse assunto seria distinto "daquele mais elevado, isto é, se existe um criador e governador do universo; a isto tem sido respondido em sentido afirmativo pelos intelectos mais elevados que já existiram" (idem, ibidem, p. 116). Aqui, parece que temos um Darwin deixando em aberto a possibilidade da existência de um Deus, o que me parece ser coerente com uma visão agnóstica de mundo. Agora, se sob o termo "religião" fosse incluído a crença em agentes invisíveis ou espirituais, a situação seria diferente para o naturalista britânico, pois 
os fatos conhecidos mostrariam que essa seria um tipo de crença universal entre os mais variados povos do planeta. Para Charles Darwin, bastou que as faculdades da imaginação, da admiração e da curiosidade, juntamente com o poder da razão, se desenvolvessem parcialmente, "que o homem pretendeu naturalmente que estava já entendendo o que estava acontecendo em volta dele e procurou vagamente indagar sobre a própria existência" (ibidem, p. 116).

O postulado sobre o princípio da descendência comum do ser humano e outras espécies de seres vivos, cujas distinções se deram lentamente por meio do processo de seleção natural, instiga a discussão sobre a origem do homem. De acordo com Charles Darwin, mesmo admitindo diferenças entre o homem e os seus parentes mais próximos na estrutura corpórea e na capacidade mental, as evidências "parecem demonstrar, da maneira mais clara, que o homem descendeu de alguma forma inferior, não obstante o fato de que até agora não puderam ser descobertos os elos de conjunção" (idem, p. 176). Em virtude das capacidades mentais e espirituais do ser humano, houve a divisão do mundo orgânico em três reinos: reino humano, reino animal e reino vegetal. Para Darwin, as capacidades espirituais não poderiam ser comparadas e classificadas pelo naturalista: "mas ele pode tentar demonstrar, precisamente como eu fiz, que as faculdades mentais do homem e dos animais inferiores não diferem em gênero, embora difiram muito em grau" (ibidem, p. 177). Darwin rejeitou a ideia de o homem formar uma ordem separada para si e citou como alternativa o trabalho de Thomas Huxley, que dividia os primatas em três subordens: os antropoides, apenas com o homem; os simioides, incluindo os símios de todos os gêneros; e os lêmures, com os seus diversos gêneros. Para investigar a origem do homem seria necessário lançar um olhar na classificação dos simioides:

\footnotetext{
Se admitimos que os símios antropomorfos foram um subgrupo natural, então, dado que o homem é semelhante a eles - não somente em todos os caracteres que possui em comum com o inteiro grupo dos catarríneos, mas em outros peculiares, como a ausência de cauda e de calosidade, e no aspecto geral - podemos concluir que algum antigo membro do subgrupo antropomorfo tem dado origem ao homem (DARWIN, 1974, p. 185).
}

Em relação ao local em que se originou o homem na fase da evolução em que seus antepassados se diversificaram do tronco dos catarríneos, isto é, do grupos de macacos, Darwin postulou que teria sido na África, região habitada por símios extintos, estreitamente afins ao gorila e ao chimpanzé, ainda que fosse difícil precisar o exato momento em que ocorreu a separação do homem do tronco dos catarríneos, uma vez que a descoberta de 
restos fósseis em toda classe de vertebrados era um processo lento e casual. Ainda sobre os antigos antepassados do homem, o naturalista inglês afirmou que eles deviam viver cobertos de pelo, sendo que ambos os sexos teriam barba, as suas orelhas provavelmente teriam pontas capazes de movimento e deveriam ter o costume de trepar em árvores e viver em regiões quentes, cobertas de florestas. E desfazendo o "encanto" da narrativa bíblica, Darwin escreveu: "atribuímos ao homem uma genealogia de prodigiosa extensão, mas, pode-se dizer, não de nobre qualidade" (DARWIN, 1974, p. 198).

No derradeiro capítulo de A origem do homem e a seleção sexual, o naturalista inglês sintetiza as ideias elaboradas ao longo de todo o livro e afirma que, a partir de suas análises e das pesquisas de outros naturalistas consultados, chegou à conclusão "de que o homem, juntamente com os outros mamíferos, descende de um antepassado comum" (DARWIN, 1974, p. 699). Para Darwin, poderia causar consolo ao homem sentir algum orgulho por ter galgado, embora não por méritos próprios, o cume da escala dos seres vivos. E o fato de ter chegado a esse topo, em vez de ter sido colocado ali desde as origens, "pode permitir que se embale na esperança de um destino ainda mais elevado num futuro longínquo" (idem, ibidem, p. 712). Contudo,

[...] cumpre que reconheçamos - pelo menos é o que me parece - que o homem, com todas as suas nobres qualidades, com a "simpatia" que experimenta pelos mais infortunados, com a benevolência extensiva, não somente a todos os homens, mas às mais humildes criaturas viventes, com o seu intelecto quase divino que penetrou nos movimentos e na estrutura do sistema solar, com todos estes enormes poderes - cumpre reconhecer que ele traz ainda na sua estrutura física a marca indelével da sua ínfima origem (DARWIN, 1974, p. 712).

Ao término de A origem do homem e a seleção sexual, ficou notório para Charles Darwin que a origem do ser humano poderia ser explicada a partir dos postulados da teoria da evolução.

\section{Considerações finais}

Após a morte de Charles Darwin, em 19 de abril de 1882, começaram a surgir rumores de que no leito de morte ele teria renunciado à sua teoria da evolução e abraçado novamente o cristianismo. O relato mais conhecido dessa possível reconversão foi dado por uma certa senhora chamada Hope em artigo publicado em uma revista religiosa mais de trinta anos após a morte dele. Ela relatou que "Darwin não só lamentou ser o autor de sua 
teoria como se reconverteu em um cristão" (SOUZA, 2009, p. 173). Embora a existência de uma senhora Hope que visitava enfermos na região em que Darwin morava tenha sido verificada por um dos seus biógrafos, James Moore, tudo leva a crer que seu relato seja falso: "O principal problema com esse relato é que foi negado por vários parentes de Darwin que estavam ao seu lado no momento da morte" (idem, ibidem, p. 173).

A história da senhora Hope, que encontrei no livro A goleada de Darwin, de Sandro de Souza, é demonstrativo do desconforto que as ideias de Darwin causaram, e ainda causam, em certos grupos sociais, especialmente religiosos. No caso, afirmar que o naturalista inglês retornou aos braços da fé cristã no momento final da vida não seria apenas uma forma de dar um novo sentido à vida dele, mas também de enfraquecer a credibilidade de sua teoria da seleção natural. Afinal, se o autor a renegou nos minutos finais de sua existência, por que continuar acreditando no evolucionismo darwinista? Como foi abordado ao longo do artigo, Darwin foi muito discreto em expor publicamente suas opiniões sobre assuntos religiosos. E em ambiente privado declarou-se agnóstico. Porém, ainda que tal história fosse verídica, ela não abalaria o potencial explicativo da teoria. Na ciência, as teorias e teses não perdem efeito se o seu autor não lhes der mais credibilidade, a não ser que novas teorias e teses contestem as anteriores. E isso pode ser feito tanto pelo autor como por outros cientistas e pesquisadores da área.

Charles Darwin evitou associar o evolucionismo com o ateísmo. Contudo, sua obra prescindiu da figura de Deus para explicar a dinâmica da origem e trajetória da vida. A teoria da evolução natural tornou possível fundamentar essa dinâmica de um modo materialista a partir da tese da descendência comum das espécies por meio da seleção natural. E mais do que isso: com essa teoria foi possível construir uma concepção evolucionista sobre o ser humano, causando uma fratura na imagem que a sociedade ocidental construiu para si com o aporte da narrativa judaico-cristã.

\section{Referências}

ARTEAGA, Juanma Sánchez. O darwinismo e o sagrado na segunda metade do século XIX: alguns aspectos ideológicos do debate. Revista Brasileira de História, São Paulo, v. 28, n. 56, p. 371-382, jul./dez. 2008.

BIZZO, Nelio. Criacionismo versus evolucionismo: literalismo religioso e materialismo darwiniano em questão. Filosofia e História da Biologia, v. 8, n. 2, p. 301-339, jul./dez. 2013. 
BIZZO, Nelio. Prefácio. In: DARWIN, Charles. A origem das espécies. São Paulo: Edipro, 2018, p. 11-23.

CARVALHO, André Luis de Lima. $O$ animal darwiniano: o status das emoções na teoria da mente em Charles Darwin. Dissertação (Mestrado em História das Ciências da Saúde) Pós-Graduação em História das Ciências da Saúde, FIOCRUZ, Rio de Janeiro, 2005.

DARWIN, Charles. A origem do homem e a seleção sexual. São Paulo: Hemus, 1974.

DARWIN, Charles. A origem das espécies. São Paulo: Edipro, 2018.

FREITAS, Jessica. No dia do orgulho ateu, nosso estado laico se cala. Terra, 12 de fevevereiro de 2015. Disponível em: <https://www.terra.com.br/noticias/brasil/no-dia-doorgulho-ateu-nosso-estado-laico-se cala, 80fc4c1d64a7b410VgnVCM10000098cceb0aRCRD.html>. Acesso em: 1 jul. 2019.

FREITAS, Leandro. A teoria evolutiva de Darwin e o contexto histórico. Revista Bioikos, Campinas, v. 12, n. 1, p. 55-62, 1998.

HOBSBAWM, Eric. A era do capital. 1848-1875. 15. ed. São Paulo: Paz e Terra, 2011.

LAMENTO informá-lo que não acredito na Bíblia nem em Jesus Cristo. El País, 08 de setembro de 2015. Disponível em: <https://brasil.elpais.com/brasil/2015/09/08/ciencia/14417065

79_830162.html>. Acesso em: 1 jul. 2019.

SOUZA, Sandro de. A goleada de Darwin: sobre o debate criacionismo/darwinismo. Rio de Janeiro: Record, 2009.

Submetido em: 19/07/2019

Aprovado em: 22/09/2019

Publicado: $15 / 12 / 2019$

\section{Notas}

\footnotetext{
' Doutor em História pela Universidade Federal do Rio Grande do Sul (2013). Atualmente é líder do Grupo de Pesquisa História Intelectual nos Séculos 19 e 20: Filosofia, Cultura e Política e do Grupo de Pesquisa História e Literatura, ambos registrados no CNPq. E-mail: ricardorussell@gmail.com
} 